\title{
Natural Gas Refinery Wastewater Treatment by Zeolites
}

\author{
SIMA REZVANTALAB ${ }^{*}{ }^{*}$, FATEMEH BAHADORI ${ }^{2}$
}

\begin{abstract}
The purpose of this study is to experimentally investigate the SAR (Sodium Adsorption Ratio) and TDS (Total Dissolved Solids) reduction in reverse osmosis (RO) concentrate, using two types of natural zeolites. In order to reduce salinity of wastewater, experiments are carried out by varying the type of zeolite, concentration of zeolite, and residence time. The results show that both zeolites can lower the SAR and TDS of wastewater; however, Rhyolitic tuff is more effective than clinoptilolite. It is observed that the concentration of zeolite has not significant effects on wastewater treatment so, using the lowest level of selected concentration reduces the cost of desalination. In addition, the effect of residence time is negligible. The experimental set up shows that the SAR reduction slop is higher than TDS.
\end{abstract}

Keywords: salinity, RO concentrates, zeolite, irrigation

\section{Introduction}

Reverse osmosis (RO) is a well-known membrane technology for treatment of wastewater and production of potable or irrigation water. The main challenge of $\mathrm{RO}$ is the concentrated waste produced during the process (Subramani et al. [1]). Several materials and technologies are employed for further treatment of Reverse osmosis concentrate, in order to reduce the rejected volume or treat it to reuse in other applications.

Jing et al. [2] evaluated the cost of the TDS removal by electricity and investigated ion treatment of wastewater produced in polymer-flooding. They revealed that electricity greatly increases the energy consumption; however, the flow rate effects on energy consumption are negligible. Mohammadesmaeili et al. [3] evaluated the RO concentrate treatment using

${ }^{*}$ Corresponding author. E-mail: s.rezvantalab@uut.ac.ir

${ }^{1}$ Department of Chemical Engineering, Urmia University of Technology, P.O. Box 57166-419, Urmia, Iran

2 Department of Chemical Engineering, Urmia University of Technology, P.O. Box 57166-419, Urmia, Iran, Email: f.bahadori@che.uut.ac.ir 
lime-soda softening process and showed that efficiency of seawater desalination using lime-soda is 80 to $90 \%$. Nkwonta and Ochieng [4] designed a pilot plant for wastewater pretreatment using charcoal and gravel. They demonstrated that filters roughness enhances efficiency of pretreatment process for mine water. They also showed that, in general, charcoal outperforms gravel.

Mrayed et al. [5] evaluated the effectiveness and flexibility of Nano Filtration (NF) in producing irrigation water from reverse osmosis concentrates. They showed that Poly Acrylic Acid (PAA) increased the ion adsorption capacity of $\mathrm{KOCH}$ membrane; however, it did not affect rejected volume of ions by the NF270 element. Rawajfeh et al. [6] investigated the influences of three layered porous media composed of Tripoli, Pozzolana, and Feldspar on seawater pre-treatment. They showed that the composite media has a significant capacity for adsorbing the seawater ions. Ghyselbrecht et al. [7] investigated the treatment of RO concentrated volume by a combination of an electro dialysis and willow field. They showed that the combination of electrodialysis and willow field is appropriate for treating $\mathrm{RO}$ concentrate. Tabatabaei et al. [8] investigated the clinoptilolite abilities on decreasing chemical and biological index of the compost factory's leachate. They showed that clay loam soil texture with pre-treatment is effective in treatment of waste water. Hassanpour Aslania et al. [9] experimentally investigated the influence of Zeolite and activated carbon on decreasing the total dissolved solids in water. Their results indicated that the efficiency of various treatment methods depends on the concentrations of chemical contaminants in water.

Most industries, specially oil and gas refineries, utilize RO plants to provide highly purified water for different plants and equipment, such as reboilers. The main problem associated with $\mathrm{RO}$ plants is the concentrated volume, i.e. when concentrated stream of $\mathrm{RO}$ is discharged back into the source of water or over land surface, it can cause many environmental damage. Sodium adsorption ratio (SAR) is a criterion of the suitability of water for irrigation. In order to reuse RO concentrate, its salinity must be reduced to prevent long term damages to environment, soil and underground water around the plant.

The main purposes of this study are treating and reusing the $\mathrm{RO}$ concentrate. For this goal, application of natural zeolites in the SAR and TDS rejection is investigated. The objective of the work is threefold: assessing the impact of two types of natural zeolites, the residence time, and the zeolite concentration. 


\section{Materials and Methods}

Reverse osmosis is a water purification technology based on membranes. $\mathrm{RO}$ is most commonly known for production of drinking water from seawater. The main problem of reverse osmosis is the salty by-product.

In this study, natural zeolites are chosen to adsorb the salty particles in the water. Zeolites have high cation exchange capacity and ion selectivity, which make them appropriate for removal of different ions from water and wastewater.

The utility plant of refinery produces about $50 \mathrm{~m}^{3} /$ day of concentrated wastewater. The concentrated stream of plant is discharged to a near road which supplies the feed water for the plant. An increase in water salinity destroys the agricultural field around the road. In order to study SAR and TDS as dependent covariates, experiments are designed in three categories:

(1) - the type of natural zeolite

(2) - the concentration of zeolite

(3) - the residence time

For this purpose, 18 samples ( 9 clinoptilolite samples and 9 Rhyolitic tuff samples) are tested and results are studied. The second parameter, concentration of zeolite, has three levels: 5,7 and $10 \mathrm{gr}$ of zeolite per $50^{\mathrm{CC}}$ of concentrate. The third parameter is the contact time with three levels: 24,48 , and $72 \mathrm{~h}$. The experiments are designed as batch and well mixed systems. After the mentioned contact time, the mixtures are filtered out and passed over activated carbon bed. Then the solutions are provided to measure SAR and TDS values.

The zeolites used as an adsorbent in the current study are obtained from Western Azarbaijan of Iran. The samples are characterized using X-ray diffractometer and chemical analysis. The chemical composition of the zeolites used in the study is shown in Table 1.

Table 1. Chemical analysis of zeolites

\begin{tabular}{|l|l|l|l|l|l|l|l|l|l|l|l|l|}
\hline Sample (\%) & $\mathrm{SiO}_{2}$ & $\mathrm{Al}_{2} \mathrm{O}_{3}$ & $\mathrm{Na}_{2} \mathrm{O}$ & $\mathrm{MgO}$ & $\mathrm{K}_{2} \mathrm{O}$ & $\mathrm{TiO}_{2}$ & $\mathrm{MnO}$ & $\mathrm{CaO}$ & $\mathrm{P}_{2} \mathrm{O}_{5}$ & $\mathrm{Fe}_{2} \mathrm{O}_{3}$ & $\mathrm{SO}_{3}$ & L.O.I \\
\hline clinoptilolite & 68.45 & 9.65 & 2.59 & 1.06 & 1.28 & 0.21 & 0.02 & 1.45 & 0.03 & 1.25 & 0.00 & 13.77 \\
\hline Rhyolitic tuff & 61.46 & 10.43 & 0.86 & 2.31 & 1.52 & 0.30 & 0.03 & 4.55 & 0.06 & 2.28 & 0.00 & 15.90 \\
\hline
\end{tabular}




\section{Results and Discussion}

In order to study the SAR and TDS values, each zeolite is added to $50^{\text {cc }}$ of RO concentrate. The three samples of 9 clinoptilolite/ Rhyolitic tuff samples are stirred for $24 \mathrm{~h}$. The residence time of the second set of clinoptilolite/ Rhyolitic tuff samples is $48 \mathrm{~h}$, and the contact time of third set is $72 \mathrm{~h}$. The next sections present the results of each experiment.

\subsection{Zeolite effects on SAR reduction}

Figure 1 represents the variation of SAR after three different contact times with clinoptilolite. It is seen that increasing the residence time from $24 \mathrm{~h}$ to $48 \mathrm{~h}$ increases the SAR rejection; however, more increase in the contact time decreases the efficiency of process.

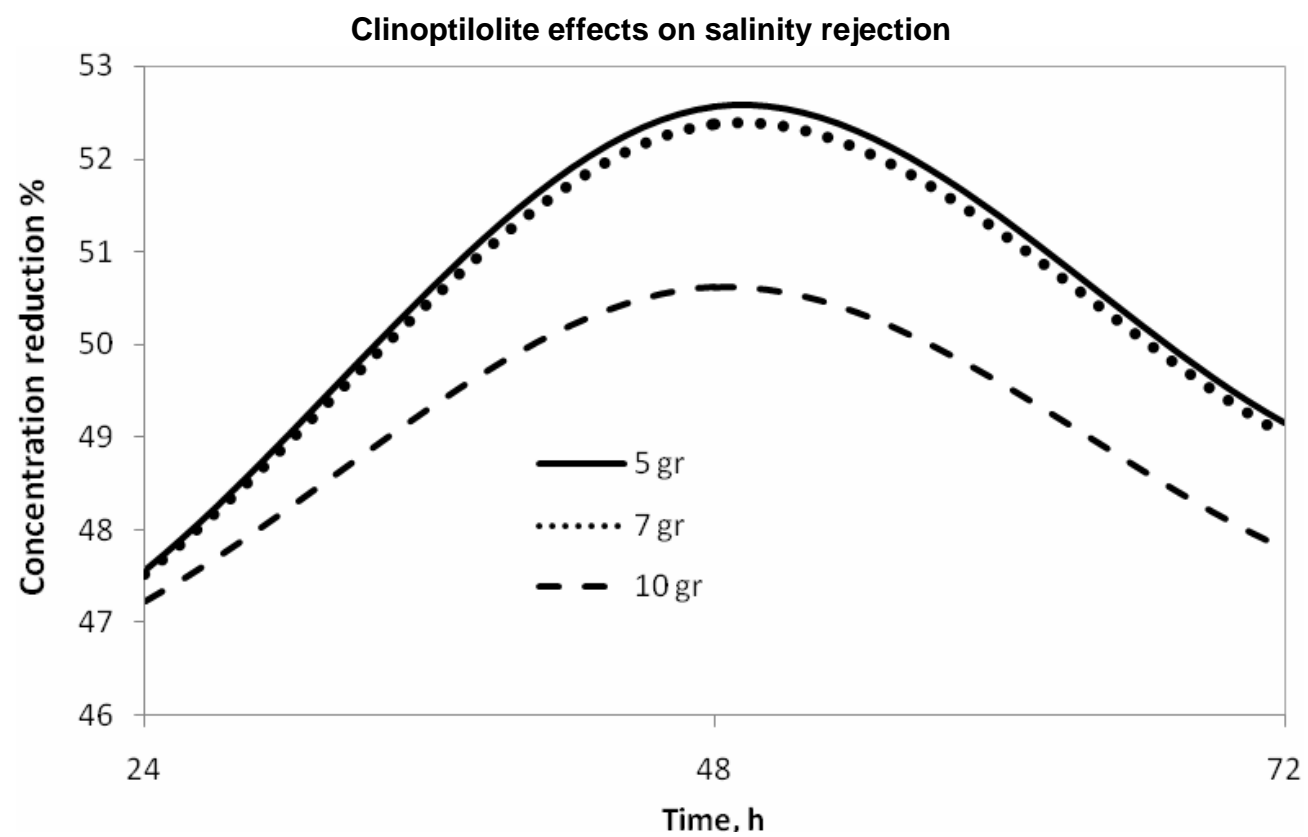

Fig. 1. Comparison of SAR reduction in different clinoptilolite concentrations 
Figure 2 shows the effects of three residence times on SAR rejection by Rhyolitic tuff. As it is shown, by increasing the contact time, at first (24-48h) the SAR reduction improves, however, by further increasing the time, the SAR value increases. It seems that the mixing of zeolites with $\mathrm{RO}$ reject is a reversible process and increasing the residence time decreases the efficiency of water desalination. In addition, maximum SAR reduction was obtained in the concentration of $5 \mathrm{gr}$ of zeolites per $50^{\mathrm{CC}}$ between three levels of zeolite concentration.

\section{Rhyolitic tuff effects on salinity rejection}

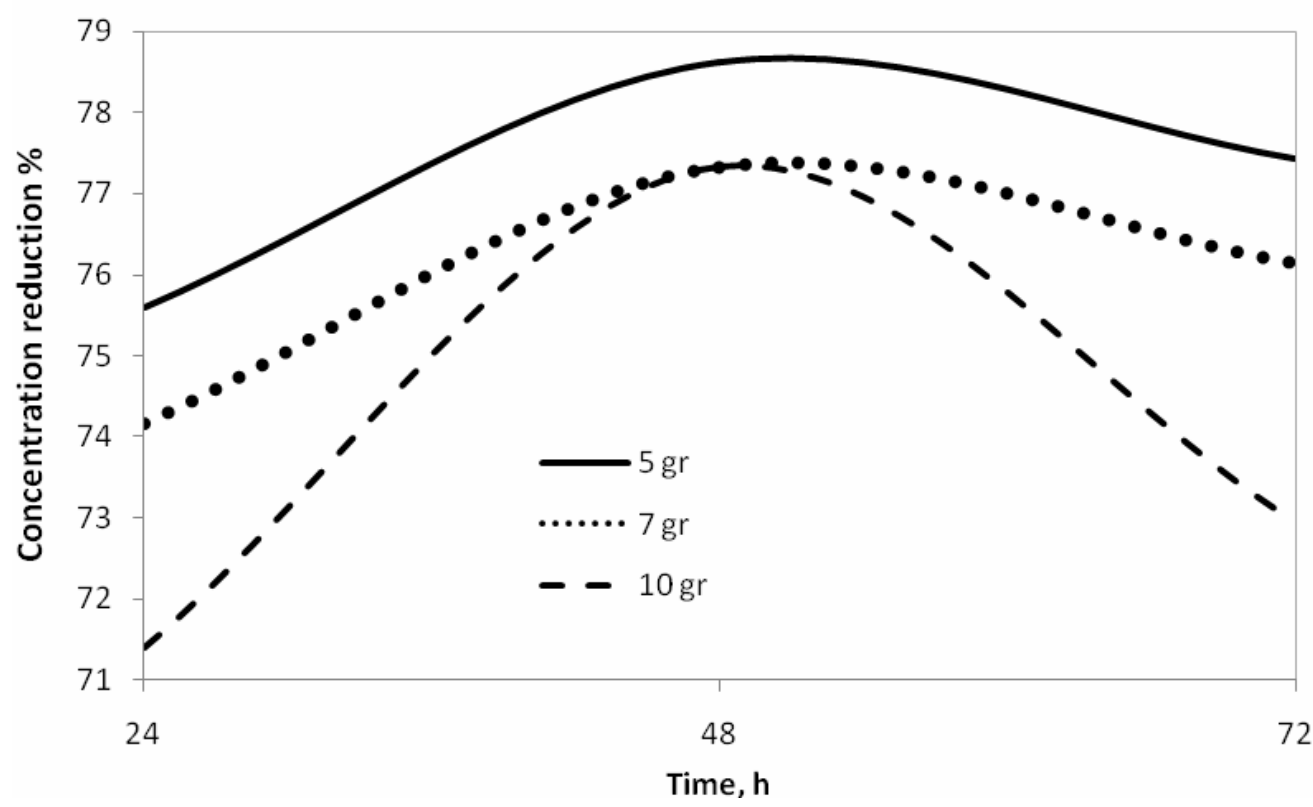

Fig. 2. Comparison of SAR reduction in different Rhyolitic tuff concentrations

\subsection{Zeolite effects on TDS reduction}

Figure 3 depicts the comparison of three residence times on TDS reduction after contacting with clinoptilolite. As it is shown, an increase in the time increases the TDS rejection; however, by further increasing the time, the slope of curves reduces. In addition, the effect of clinoptilolite concentration on TDS reduction is negligible. 


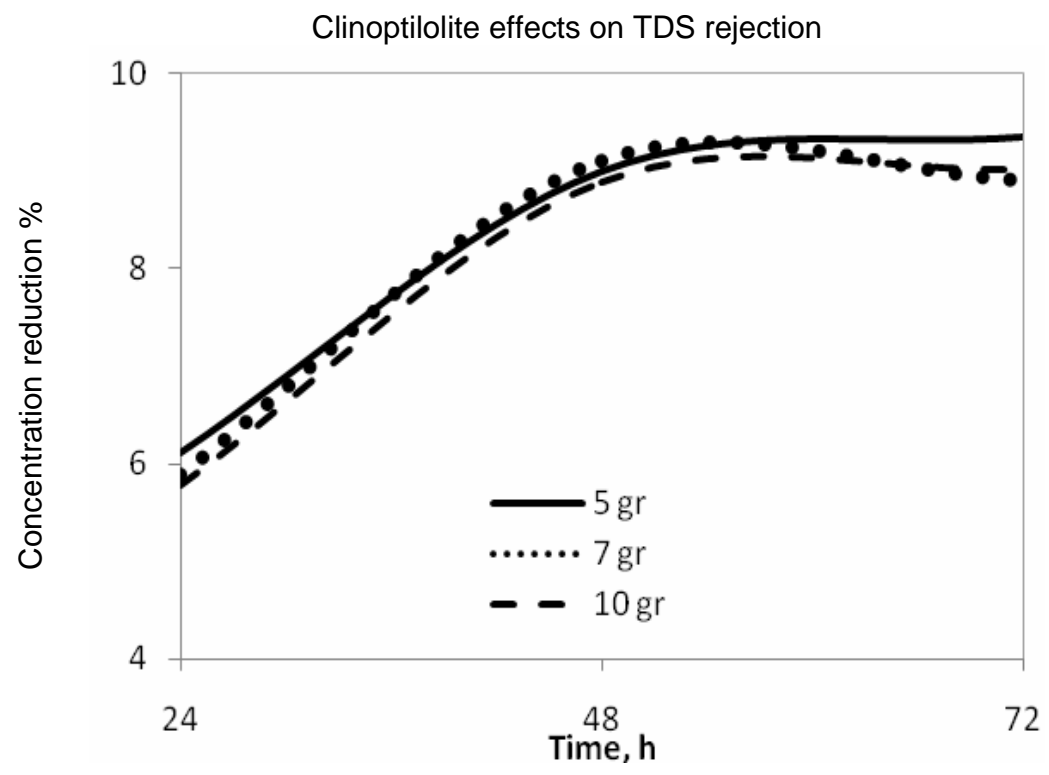

Fig. 3. Comparison of TDS reduction in different clinoptilolite concentrations

Rhyolitic tuff effects on TDS rejection

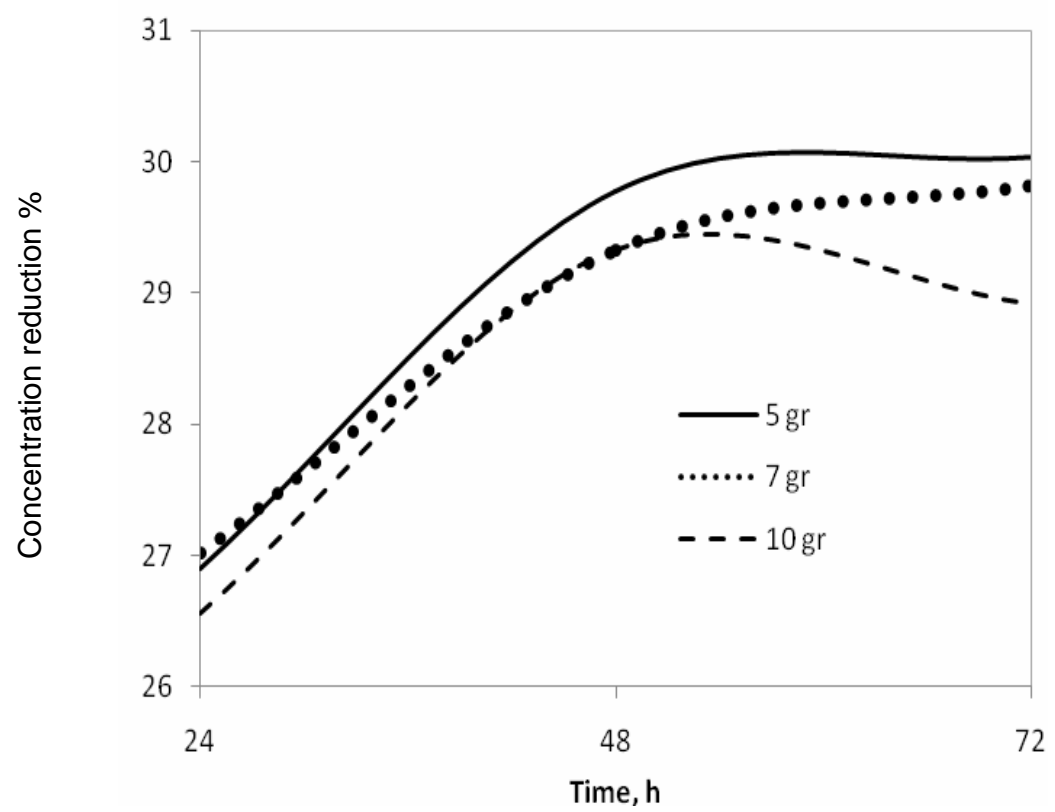

Fig. 4. Comparison of TDS reduction in different Rhyolitic tuff concentrations 
Figure 4 depicts the effects of three contact times on TDS reduction after contacting with Rhyolitic tuff. As it is shown, the curves are near each other and the concentration of Rhyolitic tuff does not significantly affect the TDS reduction.

\section{Conclusion}

In this paper, in order to reuse in irrigation, the application of natural zeolites is investigated for salinity reduction of $\mathrm{RO}$ concentrate. It is seen that clinoptilolite lowers the water salinity; however, Rhyolitic tuff is more effective than clinoptilolite in water treatment. It is observed that for both zeolites, effects of concentration on SAR and TDS reduction are negligible. In addition, it can be neglected from the effect of residence time on salinity reduction.

\section{References}

[1] Arun Subramani, Joseph G. Jacangelo, “Treatment technologies for reverse osmosis concentrate volume minimization: A review", Separation and Purification Technology 122 (2014) 472-489

[2] Guolin Jing, Xiaoyu Wang, Hai Zhao, "Study on TDS removal from polymer-flooding wastewater in crude oil: Extraction by electrodialysis", Desalination 244 (2009) 9096

[3] Farah Mohammadesmaeili, Mostafa Kabiri Badr, Morteza Abbaszadegan, Peter Fox, "Byproduct recovery from reclaimed water reverse osmosis concentrate using lime and soda-ash Treatment", Water Environ. Res. 82 (2010) 342

[4] O.I. Nkwonta, G.M. Ochieng, "Total dissolved solids removal in wastewater using roughing filters", Chemical Sciences Journal 2010: CSJ-6

[5] S.M. Mrayed, P. Sanciolo, L. Zou, G. Leslie, "An alternative membrane treatment process to produce low-salt and high-nutrient recycled water suitable for irrigation purposes", Desalination 274 (2011) 144-149

[6] Aiman E. Al-Rawajfeh, Khaldoon Al-Whoosh, Reyad Al Dwariri, Ahmad AlMaaberah, Amer Tarawneh, "Pre-treatment of desalination feed seawater by Jordanian Tripoli, Pozzalana and Feldespar: Batch experiments", Chemical Industry $\mathcal{E}$ Chemical Engineering Quarterly 17(2) (2011) 163-171

[7] Karel Ghyselbrechta, Emmanuel van Houtteb, Luc Pinoyc,d, Johan Verbauwhedeb, Bart van der Bruggend, Boudewijn Meesschaert, "Treatment of RO concentrate by means of a combination of a willow field and electrodialysis", Resources, Conservation and Recycling 65 (2012) 116-123

[8] Sayyed-Hassan Tabatabaei, Payam Najafi, Sayyed Mohammad Javad Mirzaei, Zohreh Nazem, Manouchehr Heidarpour, Shapoor Hajrasoliha, Majid Afyuni, Habiballah Beigi Harchegani, Esmaeel Landi, Leila Akasheh, Mohammad Zamanian, Mehdi Barani and Houssin Amini, "Compost leachate recycling through land 
treatment and application of natural Zeolite", International Journal of Recycling of Organic Waste in Agriculture 1 (2012) 2

[9] S. Hassanpour Aslania, H. Ghafourianb, M. R. Ardakanic, S. Torabid, “Feasibility study of reducing the total dissolved solids (TDS) from contaminated water in radish plant (Raphanus Sativus) using nano activated carbon and zeolite", JNS 3 (2013) 219-225 